\title{
Firm Digital Papulonodules in an Infant
}

\author{
Jiahui Hu, MD; Longfei Zhu, PhD; Nicholas Sikun Chen, PhD; Songmei Geng, PhD
}

\section{Eligible for 1 MOC SA Credit From the ABD}

This Dermatopathology Diagnosis in our print edition is eligible for 1 self-assessment credit for Maintenance of Certification from the American Board of Dermatology (ABD). After completing this activity, diplomates can visit the ABD website (http://www.abderm.org) to self-report the credits under the activity title "Cutis Dermatopathology Diagnosis." You may report the credit after each activity is completed or after accumulating multiple credits.

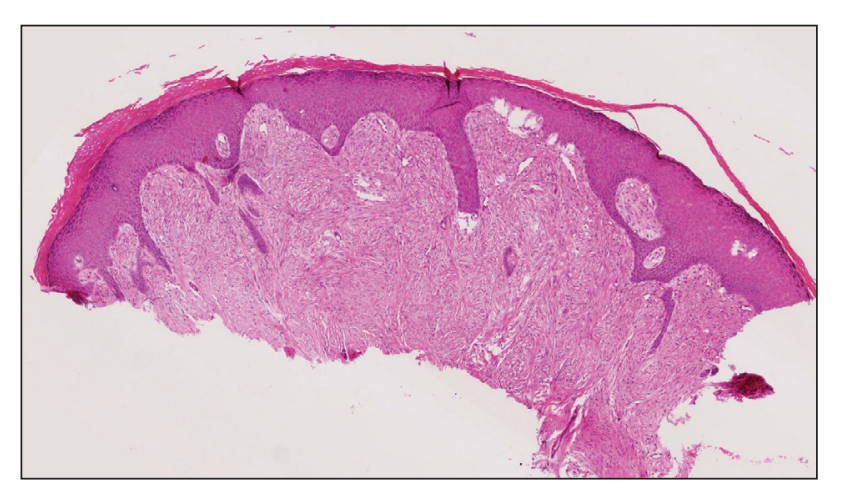

H\&E, original magnification $\times 40$.

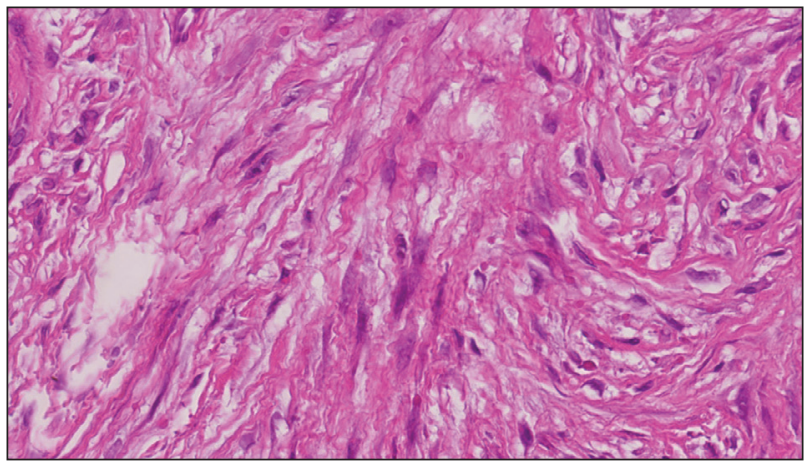

H\&E, original magnification $\times 400$.
A 3-month-old girl presented with papulonodules on the distal left ring finger. Initially the lesions were thought to be insect bites but became firm over the course of 3 weeks and then gradually increased in size over 2 months. Physical examination revealed a $0.5 \times 0.5-\mathrm{cm}$ firm nodule and a $0.2 \times 0.3-\mathrm{cm}$ firm papule on the radial aspect of the left ring finger over the distal interphalangeal joint. There was no deformity or dysfunction of the finger. Radiography showed soft tissue swelling without bony abnormalities. The lesions were excised; however, a new fleshy nodule reappeared 1 month postoperatively on the radial aspect of the left ring finger over the distal interphalangeal joint. The patient did not seem bothered by the lesions and was in good general health.

\section{THE BEST DIAGNOSIS IS:}
a. dermatofibroma
b. digital myxoid cyst
c. giant cell tumor of the tendon sheath
d. infantile digital fibromatosis
e. keloid

Drs. Hu, Zhu, and Geng are from the Department of Dermatology, Second Affiliated Hospital, School of Medicine, Xi'an Jiaotong University, China. Dr. Chen is from the University of Southampton, United Kingdom.

The authors report no conflict of interest.

Correspondence: Songmei Geng, PhD (gsm312@yahoo.com).

doi:10.12788/cutis.0382 


\section{THE DIAGNOSIS: Infantile Digital Fibromatosis}

nfantile digital fibromatosis (IDF) is a rare benign neoplasm of infancy prone to recurrence after resection but not to metastasis. It usually is limited to the fingers and toes. ${ }^{1}$ One-third of cases occur at birth. Most patients develop clinical symptoms within the first year of life, but presentation can occur in adolescents and adults. The exact etiology and pathogenesis of IDF remain unclear, but trauma is thought to be a trigger.

Physical examination reveals single or multiple smooth, round, pink papules or nodules confined to the sides and backs of the fingers, sparing the thumb and first toe. ${ }^{2,3}$ The nodules typically are firm, less than $2 \mathrm{~cm}$ in diameter, and often painless. Infantile digital fibromatosis exhibits an indolent progression followed by a rapid growth phase during several months, which may lead to functional impairment and joint deformities. ${ }^{4,5}$ Histopathology displays spindle cells with eosinophilic cytoplasmic inclusions that range from round to oval with uneven distribution, lack of refraction, and a large size difference $(3-15 \mu \mathrm{m}) .{ }^{6}$ The inclusions are deep red with Masson trichrome staining and can express smooth muscle actin and calponin. Tumor cells usually express vimentin, smooth muscle actin, calponin, and desmin but fail to express S-100 protein. The Ki67 proliferation index is $2 \%$ to $15 \%$. ${ }^{6,7}$

Nonsurgical treatments for IDF include topical imiquimod, topical or intradermal injection of glucocorticoids, and intradermal injection of 5-fluorouracil. Complete resection should be reserved for cases with invasive growth that may lead to joint deformities, tendon or ligament involvement, digit or contracture deformity, and complications such as decreased joint mobility. Although there is a recurrence rate of up to $50 \%$ after excision, most lesions eventually will spontaneously regress and will leave no scar. ${ }^{8-10}$

The clinical and histopathologic differential diagnoses of IDF include other cutaneous diseases that occur in the digits. A dermatofibroma is a round, firm, fibrohistiocytic nodule that mainly occurs on the extensor limbs. Histopathology includes both fibrous and cellular types. ${ }^{11}$ Histologic analysis shows an ill-defined dermal proliferation of spindled fibroblasts with pale eosinophilic cytoplasm and bland fusiform nuclei growing in bands or fascicles that trap collagen fibers at the periphery (Figure 1). Generally, dermatofibromas have marked epidermal hyperplasia, which differs from IDF.

A digital myxoid cyst is characterized by a fleshcolored, hemispherical, and translucent cystic nodule that arises from the dorsum of the distal interphalangeal joint. ${ }^{12}$ It commonly is associated with injury and chronic pressure. Translucent viscous liquid may flow out when the cyst is punctured, a hallmark feature of this entity. Clinical variants of myxoid cyst include myxomatous and ganglion types. Histopathology reveals excessive mucin deposited in the dermis, and the surrounding collagen is compressed to form the pseudocyst (Figure 2).

A giant cell tumor of the tendon sheath presents with asymptomatic nodules or lumps. Lesions frequently are localized to the tendon sheath, especially on the fingers and wrists, with no malignant tendency or propensity for spontaneous regression. ${ }^{13}$ The local recurrence rate is as high as $45 \%$, which is related to surgical resection insufficiency. ${ }^{14}$ Histopathologic examination shows lobulated tumor tissue surrounded by dense fibrosis. The tumor cells are histiocytic with scattered giant cells (Figure 3). The characteristic osteoclastlike giant cells have eosinophilic cytoplasm and irregularly arranged nuclei in varying numbers.

Keloids are connective tissue hyperplasias caused by skin injury. Histopathologically, keloids are characterized by nodules of thick hyalinized collagen bundles and

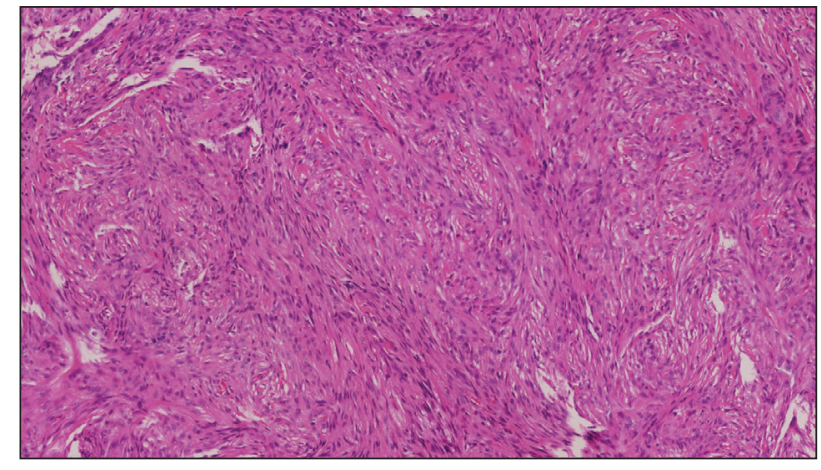

FIGURE 1. Dermatofibroma. Spindled fibroblasts in bands or fascicles (H\&E, original magnification $\times 100)$.

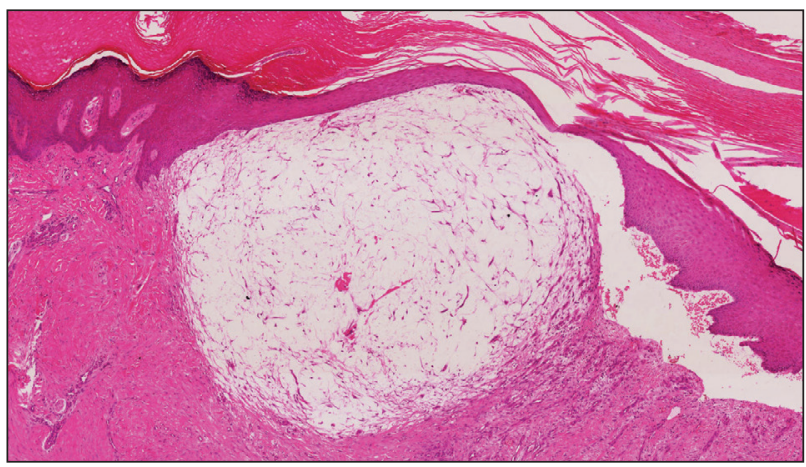

FIGURE 2. Digital myxoid cyst. Pseudocyst with extensive mucin deposition (H\&E, original magnification $\times 100)$. 


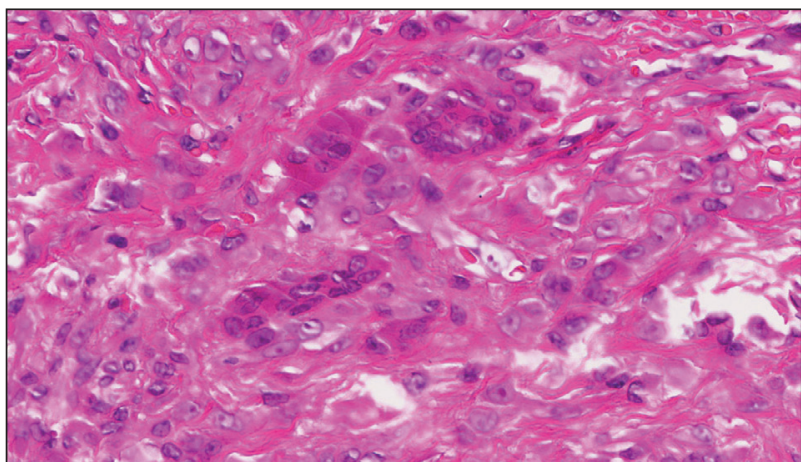

FIGURE 3. Giant cell tumor of the tendon sheath. Osteoclastlike giant cells show hypereosinophilic cytoplasm and irregularly arranged nuclei varying in numbers (H\&E, original magnification $\times 400$ ).

whorled fibroblasts (Figure 4). No inclusions in the fibroblasts and a history of trauma can differentiate keloids from IDF.

\section{REFERENCES}

1. Marks E, Ewart M. Infantile digital fibroma: a rare fibromatosis. Arch Pathol Lab Med. 2016;140:1153-1156.

2. Botelho LF, Matsushigue T, Enokihara MM, et al. Case for diagnosis. An Bras Dermatol. 2012;87:493-494.

3. Paloni G, Mattei I, Salmaso R, et al. Infantile digital fibromatosis. Arch Dis Child. 2013;98:308

4. Girgenti V, Restano L, Arcangeli F, et al. Infantile digital fibromatosis: a rare tumour of infancy. report of five cases. Australas J Dermatol. 2012;53:285-287.

5. Eypper EH, Lee JC, Tarasen AJ, et al. An algorithmic approach to the management of infantile digital fibromatosis: review of literature and a case report. Eplasty. 2018;18:E19.

6. Laskin $\mathrm{WB}$, Miettinen $\mathrm{M}$, Fetsch JF. Infantile digital fibroma /fibromatosis: a clinicopathologic and immunohistochemical

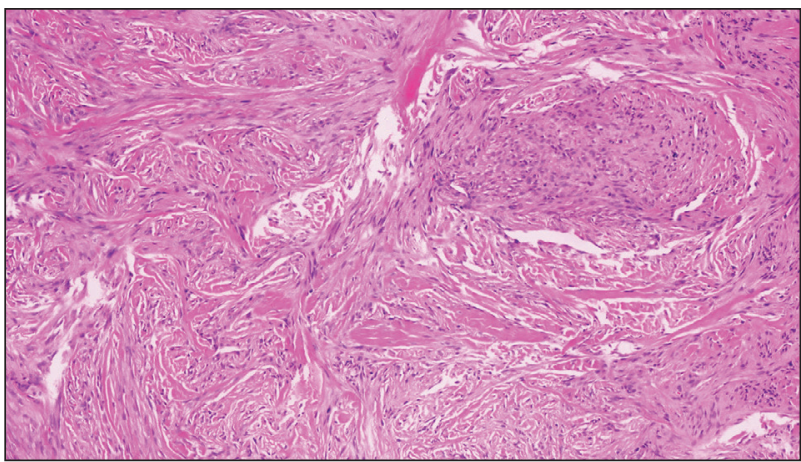

FIGURE 4. Keloid. Thick, uniform, eosinophilic, reddish-stained collagen bundles in the dermis arranged haphazardly (H\&E, original magnification $\times 100$ ).

study of 69 tumors from 57 patients with long-term follow-up. Am J Surg Pathol. 2009;33:1-13.

7. Henderson H, Peng YJ, Salter DM. Anti-calponin 1 antibodies highlight intracytoplasmic inclusions of infantile digital fibromatosis. Histopathology. 2014,64:752-755.

8. Campbell LB, Petrick MG. Mohs micrographic surgery for a problematic infantile digital fibroma. Dermatol Surg. 2007;33:385-387.

9. Ochi H, Puhaindran ME, Tan KW. Firm digital papulonodules in a young boy. Int J Dermatol. 2019;58:91-92.

10. Albertini JG, Welsch MJ, Conger LA, et al. Infantile digital fibroma treated with Mohs micrography surgery. Dermatol Surg. 2002;28:959-961.

11. Alves JV, Matos DM, Barreiros HF, et al. Variants of dermatofibromaa histopathological study. An Bras Dermatol. 2014;89:472-477.

12. Meyers AL, Fallahi AKM. Digital Mucous Cyst. StatPearls Publishing; 2020

13. Zhao Q, Lu H. Giant cell tumor of tendon sheath in the wrist that damaged the extensor indicis proprius tendon: a case report and literature review. BMC Cancer. 2019;19:1057.

14. DiGrazia S, Succi G, Fragetta F, et al. Giant cell tumor of tendon sheath: study of 64 cases and review of literature. G Chir. 2013;34:149-152.

Kowtoniuk RA, Liu YE, Jeter JP. Cutaneous cold weather injuries in the US Military. Cutis. 2021;108:181-184, 202. doi:10.12788/cutis.0363

In the article above from the October 2021 issue, an author's name was spelled incorrectly. The correct byline appears below. The article has been corrected online at www.mdedge.com/dermatology. We apologize for the error.

Robert A. Kowtoniuk, DO; Yizhen E. Liu, MD; Jonathan P. Jeter, MD 